\title{
On Semantics of Blessings \& Curses in English and Armenian: Linguo-Cultural Perspective
}

\author{
A. S. Hovhannisyan ${ }^{1}$ L. Ts. Nikolyan ${ }^{2}$ \\ ${ }^{1}$ Shirak state University, Gyumri, Armenia, ${ }^{2}$ Gyumri, Armenia \\ E-mail: a_hovhannisyan@mail.ru,_liananikolian21@gmail.com \\ Paper received 30.08.18; Accepted for publication 07.09.18.
}

https://doi.org/10.31174/SEND-Ph2018-182VI53-07

\begin{abstract}
The interest in linguo-cultural studies has always instigated much research. The article aims at exploring the curses and blessings in English and Armenian linguo-cultures. It focuses on idioms, broadly defined, and its relation to curses and blessings. Although much has been said about idioms, there are still significant gaps in our treatment of these linguistic units. Special focus is laid on semantic patterning of curses and blessings in two different languages for revealing their common and distinctive features.
\end{abstract}

Keywords: Curse, blessing, phraseological unit, sentence-lawn idioms, semantics, Holy Bible.

1. Introduction. Oxford Dictionary defines blessing as "God's favor and protection or a prayer asking for divine favour and protection, grace said before or after a meal, a beneficial thing for which one is grateful, a person`s sanction or support" /https://en.oxforddictionaries.com/definition/blessing/.

Barak is the Hebrew word most often translated "bless" meaning to praise, congratulate or salute. In Genesis 1:22 we see the first time when God blessed the sea creatures and birds, telling them to be fruitful and multiply on Earth. Like to it, in verse 28, God said the similar blessing to Adam and Eve. He added that they were to be dominant on the rest of creations. When God called Abram to go to the Promised Land (Genesis 12:1-3), he promised to bless him, make his name great and, through him, to bless all the families on the Earth. Here the blessings are only associated with happiness and welfare, both for Abraham and others. In Genesis 22:1618, God again blesses Abram and adds that blessing is due to his obedience to God's commands (https://www.gotquestions.org/blessing-Bible.html).

God's design originally for His creatures, human beings included, was for them to have welfare, serenity and peace. But when sin appeared in the world it ruined this design. God's final blessing is the new life and forgiveness that comes after His son's- Jesus Christ's resurrection. We enjoy material blessings every day which are temporal, but the spiritual blessings given to us are eternal. According to the Psalm, "Blessed is he whose help is the God of Jacob, whose hope is in the LORD his God" (Psalm 146:5).

Curse is a solemn utterance intended to evoke a supernatural power to inflict harm or punishment on someone or something. It is an offensive word or phrase used to express anger or annoyance (https://contemporaryshaman.wordpress.com /2013/11/25/the-power-of-a-curse).

The curse effectiveness was a matter of arguments. The source of existing belief in the effectiveness of cursing was not in theology, but in popular beliefs and views. The general populace believed that if the curser was unfairly treated, then the chance of the curse to be effective was great, whereas unprovoked and unjustified curses would damage cursers

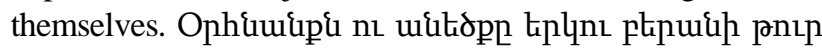

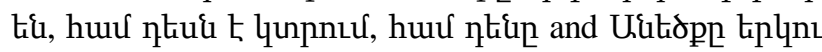
ptipuuula unıp t. This comes from Christianity. The Golden rule of the Bible says "So whatever you wish that others would do to you, do also to them, for this is the Law and the Prophets" (Mattew 7:12).

Curses, as part of witchcraft fantasy, could be regarded a powerful means to circle and express the inner fears and anxieties within different spaces throughout early modern times. Thus, in this way, curses, as "flashing words", became the most powerful weapon of the witch. In 1624, parliament passed an Act against blasphemous swearing and cursing. However, this did not prevent the spread and existence of the curse myths within the community.

\section{Method}

\subsection{Blessings/Curses as Sentence-lawn Idioms}

In the next step of our research a very important question is put forward: to define the type of relations between the idiom on the one hand and the blessings, curses on the other hand. How is this problem viewed in English and Armenian philology?

An idiom is a stable combination of words with a fully or partially figurative meaning (Koonin, 1970:210). The term "idiom" generally implies that the essential feature of the linguistic units under consideration is idiomaticity or lack of motivation. Idioms are viewed as functionally and semantically inseparable units. No element in an idiom can be changed. They are comparatively stable and reproduced as single unchangeable collocations (Ginzburg, 1979:74). Thus, for example, the constituent for red in the idiom red tape cannot be substituted by any other adjective denoting color (blue, white, etc.) as a change of the adjective would involve a complete change in the meaning of the whole group. In the same way, other adjective cannot be used instead of green in the blessing $U_{p} l_{\eta}$ quiquz .Grammatical structure of idioms is to a certain extent stable. Thus, the noun upl (sun) and tape in the above phrases cannot be found in the plural or in combinations with other markers of the category of definiteness (upluu, upln quifuus, a tape, the tape, tapes).

As for the linguistic status of idioms they can function as a single word, a word-combination and a sentence as well.

What brings idioms closer to words? Idioms take an intermediate position between words and sentences. Some idioms are given birth by a single word and they are named word-idioms or words equivalent to idioms. For example: He is a selfy-old fox: often disapproving a person who is clever and able to get what they want by influencing or risking other people (Oxford dictionary, p. 853). The metaphorical shift takes place on the analogy of fox as an animal and as a person. Similar to single words idiomatic constructions are not speech units as are not created in speech and are introduced as ready-made units of language level. They both express one notion and function as a part of a sentence.

The closeness of single words and phraselogical units is vividly expressed in parallel synonymous set, where each single word works parallelly with its corresponding synony- 
mous team framed as an idiom: in English to hurry (single word) and its parallel synonymic set to make haste (idiomatic expressions), in Armenian utinutil (single word)-

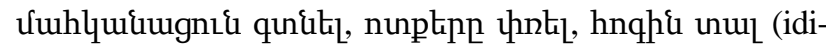
omatic expressions). The function of idioms in speech is expressive and intensifying as compared to their one-word synonymous equivalents.

There is a pressing need for criteria distinguishing idioms not only from words but from compound words as well. Prof. Smirnitsky considers a phraseological unit to be similar to the word because of the idiomatic relationship between its part resulting in its semantic unity and permitting its introduction into speech as something complete (Ginzburg:206). In compound words as well as in phrases the immediate constituents obtain integrity and structural cohesion that make them function in a sentence as a separate lexical unit (Arnold:60). In compound words the process of integration is much more advanced.

Sentence-lawn idioms, as the term speaks itself, come from simple or multiple sentences and correspondingly are similar to them in their structure having one or two predications. Verb takes a central part in this construction and being intermediately located it shares a border with the subject (with the agent of an action) and with its verbal complements. However, sentence-lawn idioms possess emotional characteristics and are peppered with numerous stylistic devices.

Idioms always express something unique about any language. They contain many differential features which make one language different from another. Idioms appear in every language. English and Armenian have thousands of them.

\subsection{Semantic Grouping of Blessings}

Blessings are divided into different semantic groups. Every group is related to a certain sphere of life and is used only on a definite occasion.

1. For mother's health. First of all blessings are connected with birth. Giving birth to a child is one of the most important occasions in every woman's life. The moment a child is born, a mother is also born. When a child is born blessings are given to a newborn child and his/her mother. People bless the mother and wish that she will get well soon.

Congratulations on the arrival of your little angel, may you soon be feeling better, may God bless you and your child with all his love and happiness.

I congratulate you on such a happy and blessed occasion. May the new baby make us all proud. Our blessings will ever shower on the new angel.

fupny han kitin untinhg uquinyluu (UZ XVI 33) /U. Zupnıрjnı\{juiq, 1975:221/

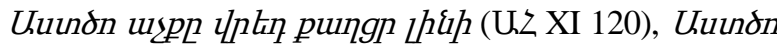

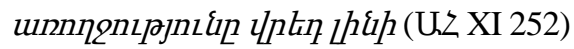

- For protecting mother from devils and an evil eye. The evil eye is a curse too. It is believed that an evil eye is by a malevolent glare. People believe that the evil eye causes bad luck, damage or even death. The phrase, "to give someone the evil eye" usually means simply to glare at the person in anger or disgust, to harm somebody by looking at them. It is believed that an evil eye more often harms women than men. Therefore people bless the mother for protecting her from an evil eye.

Dear Lord your gifts are many. One of the greatest gifts you have given is this child. Thank you for his life. Watch over him each day. May he and his mother be safe and free from harm and from an evil eye.

\section{fupàn Fuph hhin (2OF 64)}

In Armenian culture people put a thorn in front of the door to protect their family from an evil eye saying Lup uisph\& sup yhnz:

2. For protecting a baby. This semantic field in its turn comprises several subgroups:

a) Blessings with the semantic centre "God"

A child is a gift from God. Each child is a reward and blessing. In the two cultures a parent begs God's blessing and protection for his/her child.

Heavenly father I ask you to put a hedge of protection around my child, God I ask you to protect my child physically, emotionally, spiritually, mentally and in every way.

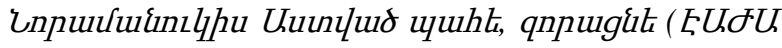
131), Uuınцud hnp nu unp hưfup uhin dlinpny

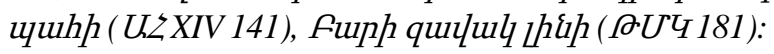

In English and Armenian blessings parents often ask for angel's protection. Angel is a spirit who is believed to be a servant of God living in heaven with Him, and is sent by God to deliver a message or perform a task.

Heavenly Father, your infinite Love for us has chosen a blessed angel in heaven and appointed him our guide during this earthly pilgrimage. And you, holy, loving angel watch over my child with all your tenderness of your angelic heart.

May angels rest their wings beside your nursery door. May God grant you always...

A sunbeam to warm you,

A moon beam to charm you,

A sheltering angel, so nothing can harm you.

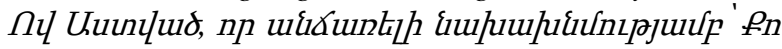

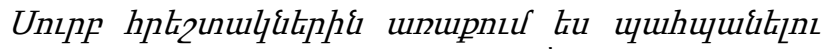

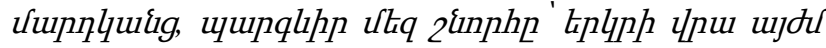

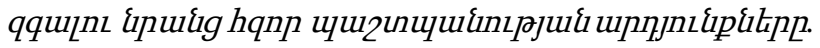

b) Blessings with the constituent "sun"

It is a well-acknowledged fact that the sun symbolizes life. $\mathrm{He}$ (the Sun) provides light and warmth to the Earth and a ray of sunshine brings happiness into our lives. There are many blessings with the constituent "sun" both in English and in Armenian.

Maythe blessing oflight be onyou, lightwithoutandlight within.

May the blessed sunlight shine and warm your heart. May you always walk in sunshine.

May the sunshine warm upon your face and rains fall soft upon your fields.

Gupulhp yupn nz untipls

fuignzliguip ounujpu y lipls

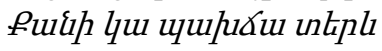

Usipunuip lnzqhu ptiq upls:

7nz\& wuph hnpny, unpny,

$\Omega_{\text {L }}$ gy/h upunhlin upliny:

These models can be prerequisite for contrastive study as in Armenian "the sun" often operates with "the moon"- a combination that cannot be found in English framing.

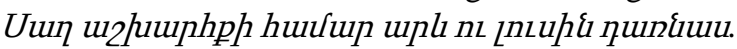

c) It should be noted that in some cases metaphor and simile come into use when some names of flowers and trees are culturally and symbolically charged in the given context. A parent compares his child with a tree or a flower. A child is like a tree which needs nurturing to its every branch to grow towards its full potential. A child is a flower that grows in the garden of life.

May you be as strong as the oak, yet flexible as the birch, 
may you stand as tall as the redwood, live gracefully as the willow, may you always bear fruit all your days on this earth.

Be like the flower who even gives its fragrance to the hand that crushes it.

In the above-mentioned examples an analogy is made between a child and trees. From linguo-cultural perspective an oak tree symbolizes strength and endurance in the two cultures. Moreover, "oak tree" is the national tree of England and is believed to be saint. The Royal Oak Day commemorates the escape of King Charles II from the grasps of the parliamentarians after his father's execution. He hid in an oak tree to avoid detection before making it safely to exile. The Major Oak is an 800-to 1000-year-old in Sherwood Forest, fabled as the principal hideout of Robin Hood (https://en.wikipedia.org/wiki/National-symbols-of-

England\#Flora-and-fauna).

As for redwood it is a very tall type of tree that grows especially in California and Oregon. The tallest redwood tree in the world is named Hyperion which reaches 379.7 feet (115.7 meters). This type of tree cannot be found in the plant life of our area and that is why the height of a child in native culture is compared with a poplar ( Fupnnzultuupnjnul hitiu).

Birch in English symbolizes growth, renewal, stability, initiation, flexibility and adaptability This tree is famous for its adaptability and ability to sustain harsh conditions with casual indifference. Proof of its adaptability is seen in its easy and eagle ability to repopulate areas damage by forest fires or clearings. However, in Armenian culture this tree is rendered as "Chupnu" and "to birch" (Chunnumuwpt $\mathrm{L}$ " to hit somebody with a bunch of a birch) in the mother tongue acquires a negative shade.

Willow tree has a long history of symbolism rooted in spirituality and cultural traditions. One of the most valuable traits of the willow tree is its flexibility. This graceful tree is one of the few trees that is capable of bending in outrageous poses without snapping. In Armenian culture willow tree is called "crying tree" and mainly grows near rivers (https://willowplaceforwomen.com/symbolism-of-thewillow-tree).

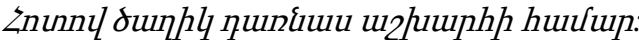

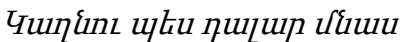

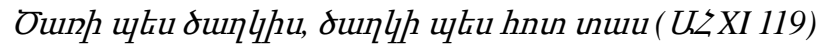

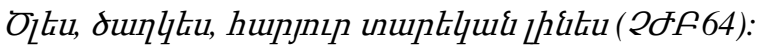

Both English and Armenian parent wishes his/her child happiness, love, good luck, as well as fame and honour that are the greatest values in every community.

May your life be full of happiness,

May your life be full of success, degrees, opportunities, promotions and progress,

May you fly towards glory in your outstanding way.

May your life be filled with joy and happiness.

May each new day bring you moments to cherish.

Utidukuu, цhunp nu uuuny/h unhpuiuuu.

3. Blessings dealing with marriage and wedding. Blessings for youth are relatively few and are mainly related to marriage. It is supposed that marriage is the most important event in our lives. Marriage is a gift- an amazing blessing from God, so the couple asks God for blessing and relatives wish a good marriage.

Dear God, we praise for your love and faithfulness. Please fill our marriage and lives with truth and cover it with blessing.

It is not enough to record the sayings of understanding on a common tablet. One must inscribe the words of wisdom upon the tablet of heart like writing on a common tablet. When writing on a tablet it is possible to see, read and remember, when writing on the tablet of heart it is possible to remember, feel and do it.

May God make your love increase and overflow for each other.

fupny quinus qupuhpn quutelp (UZ XVI 25) /U. zupnıpjnı\&jui, 1975:224/.

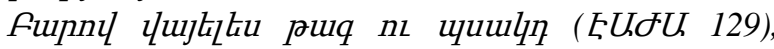

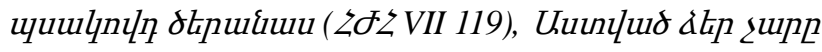
puph uilh:

In Armenian weddings "kospand" is tied. It consists of two threads, one is red and the other is green. It is the symbol of bridegroom.

In English and Armenian cultures people bless the bride and the bridegroom to be happy and have many children.

Health and a long life, land without rent to you, a child every year to you.

May God be with you and bless you,

May you see your children's children.

May you be poor in misfortune, Rich in blessings.

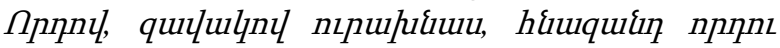
untip plithu, dztp, duinltp, ylupn pninptip.

4. Blessings for birthday. People are blessed on important events such as on their birthday. On that day family members, friends, relatives give many gifts and blessings.:

$$
\begin{aligned}
& \text { God bless you today, } \\
& \text { God bless you today, }
\end{aligned}
$$

God bless you and keep you

Today and always.

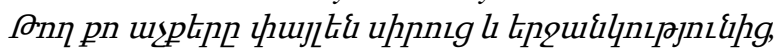

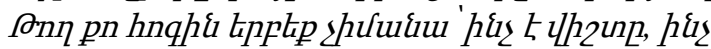

$$
\text { puihipd: }
$$

\subsection{Semantic Grouping of Curses}

The word "curse" means a malevolent appeal to a supernatural being for harm to come to somebody or something, or the harm that is thought to result from this or to appeal malevolently to a supernatural being for harm to come to somebody or something. Curse always has a cause. Proverb 26:2 says "Like a sparrow in its flitting and a swallow in its flying so a curse without a cause cannot alight".

When someone curses he/she wants to punish him/her. Based on the type of punishment curses are divided into two main groups.

\section{Wishing physical punishments}

a) The strictest punishment is death. The majority of curses are based on it /U. Zupnıpjnıljuid, 1975:199/ such as:

May you die, slowly ripped apart and eaten still alive.

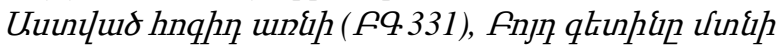
( $\measuredangle U U 4), U$ uhluki plipuin quuu ( $2 \sigma Z$ VII 105)

There are some curses in which the speaker wishes the interlocutor to suffer terribly before dying or to get into an accident.

May you die a horrible and painful death with scorpions feeding off of your eyeballs, and cats eating your liver.

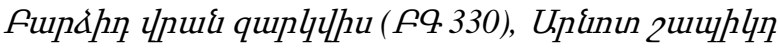

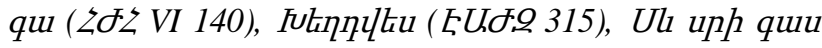
(U¿XI 124) /U. Zupnıpjnı\&juil, 1975:200/

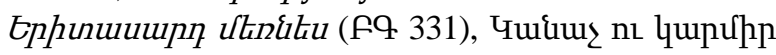

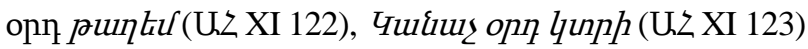


Curses in Armenian culture have many peculiarities. They sound much stronger and crueler than English ones. One of the terrible punishments for a parent is the death of the child. The parents had many hopes and dreams for their child. The death of a child signifies the loss of future, hopes and dreams.

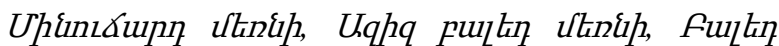

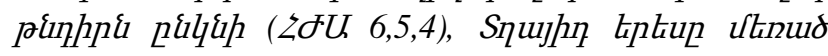
unkuqutu (UhK 128)

b) Another cruel curse deals with illness. The speaker curses someone to suffer from horrible illness. This group comprises:

\section{- Physical pains}

The Lord will strike you with disease, with fever and inflammation, with scorching heat and drought, with blight and mildew which will plague you until you perish.

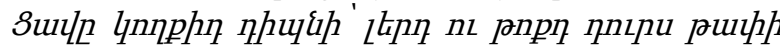

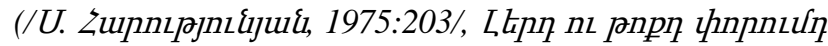

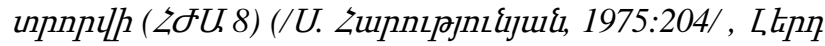
nu qhquupn huizlh ( $2 \sigma U 6)$

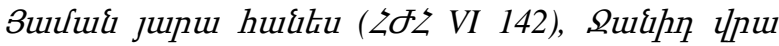

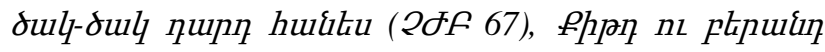

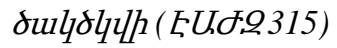

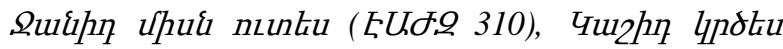
(<< fuqufuyltup>>, 1902:479)

\section{- Blindness}

Lord will give you an anxious mind and blind eyes.

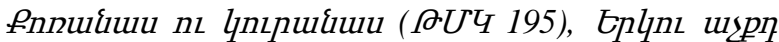

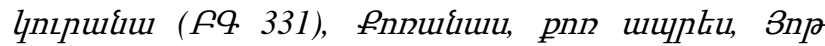

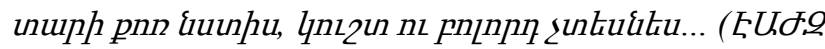
313)

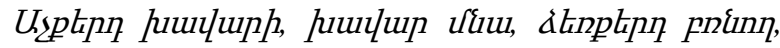

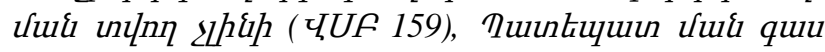
( $८ \sigma U 9)$

\section{- Madness}

The Lord will affect you with madness and confusion of mind.

The sights you see will drive you mad.

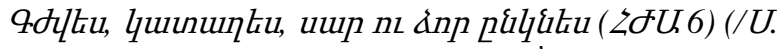
zupnıpjnıEjui, 1975:205/, Yuununtu' 'Shun nuntu

\section{Wishing social-civil punishments}

Many curses deal with poverty. The speaker wishes someone to lose all his property:

In hunger and thirst, in nakedness and dire poverty, you will serve the enemies the Lord sends against you.

Uuunlud hugn lunph (ULXI 122), Uh Lhontp hughs

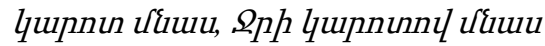

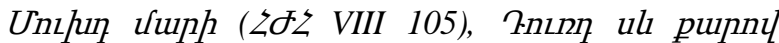

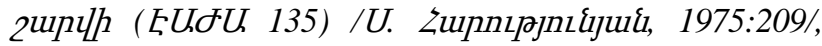

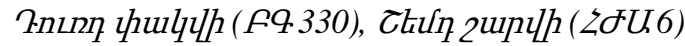

3. Result. Thus we can arrive at the conclusion that the origin of both blessings and curses is The Holy Bible. A blessing is a statement of good will and happiness that is said about another, as well as the condition that fulfills those good words. First of all God blessed birds, animals then first human beings and everything that he created. The blessings are merely associated with prosperity and happiness in the Bible. The best life can be given only to those people who love and fear God and live according to His Word.

When a person curses another person, we do not understand this as a mere wish, but fierce, that disaster should overtake him/her. Curse always has a cause. If there is a curse there is a cause for it. In many cases in order to be released from the curse it is important to discover the cause. Curses are the result of sin and disobedience. Death itself passed on from Adam as the consequence of sin. In the Bible we can see sickness, pestilence, blindness and madness. It is an expression of the universal law of sowing and reaping. The general populace believed that if the curser was unjustly treated, then the chance of the curse to be effective was great, whereas unprovoked and unjustified curses would damage cursers themselves.

From linguistic perspective blessings and curses are considered to be idioms both in English and in Armenian. Semantically blessings and curses are inseparable as the meaning of an idiom is metaphorical rather than literal. They can contain uncommon word combinations which when we understand in their literal meaning are normally unallocable. Idioms are grammatically inseparable as well. Its members cannot be grammatically changed and they function in a sentence as one member.

One of the features of both blessings and curses is that they often continue from generation to generation. This means that a person who is experiencing either a blessing or a curse may not easily discern where it comes from, because it may be in the past, even hundreds of years ago.

A person is blessed since the moment of birth. There are many blessings for the mother and for a baby in English and Armenian. People congratulate and ask God to protect mother and child. For a child people ask God's and angels' protection, health, happiness, good luck comparing him/her with a tree or a flower. People bless in important life events such as on birthday, wedding etc. Thus English and Armenian blessings have more similarities than differences, the main difference between them being different kinds of trees, flowers etc. used in them.

Of particular interest in contrastive languages are curses. In both languages the strictest punishment in curses is death, in some of them the wish is to suffer terribly before dying. Many curses deal with illness, physical pains, madness, blindness, poverty etc. Thus English and Armenian curses have more differences than similarities.

\section{REFERENCES}

1. Arnold I. V., (1973), Lexicology of Modern English: Vishchaya Shkola $\left(2^{\text {nd }} e d.\right)$, Moscow

2. Ginzburg R. S., (1979), A Course in Modern English Lexicology, Moscow

3. Holy Bible, Old and New Testaments

4. Koonin A. V., (1970), English Phraseology, Moscow

5. Oxford Advanced Leraner's Dictionary of Current English, (2010), Eighth edition, Oxford University Press

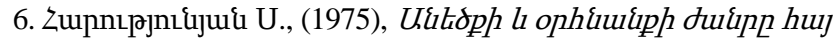

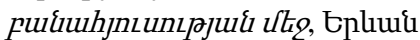

8. Htttp://www.crosswalk.com/faith/prayer/prayers/40-powerfulblessings-to-pray-over-your-children.html

9. https://en.wikipedia.org/wiki/National-symbols-ofEngland\#Flora-and-fauna

10. https://willowplaceforwomen.com/symbolism-of-the-willowtree/

11. https://en.oxforddictionaries.com/definition/blessing

12. https://www.gotquestions.org/blessing-Bible.html

13. https://contemporaryshaman.wordpress.com/2013/11/25/thepower-of-a-curse/ 